\title{
ORIGINAL
}

ARTICLES

\section{Certified Nurse Midwives as Teachers of Family Medicine Residents}

Narges Farahi, MD; Elizabeth Neylan; Johanna Silbersack, MSW; Julia Oat-Judge, MD; Philip D. Sloane, MD, MPH

BACKGROUND AND OBJECTIVES: The high quality of obstetric care provided by certified nurse midwives (CNMs) has led some to hypothesize that collaboration with CNMs may encourage more family medicine (FM) residents to subsequently practice maternity care. Our goal was to understand the current state of CNM involvement in FM resident education.

METHODS: We conducted two surveys: one to a random sample of $180 \mathrm{FM}$ program directors, and one to $147 \mathrm{CNMs}$ involved in medical education. The surveys examined the nature, prevalence, and attitudes regarding CNM involvement in FM residency training.

RESULTS: The surveys' response rate was 59\% from FM program directors and $58 \%$ from CNMs. Thirty-six percent of FM directors reported no CNM involvement in their residency programs, $26 \%$ reported minimal interaction, and only $6 \%$ reported a fully integrated model with CNMs on faculty. Eighty-eight percent of CNMs and $64 \%$ of program directors reported a prefence for increased interaction. Programs with highly involved CNMs reported 33\% of graduates subsequently practicing prenatal care, with only $13 \%$ of graduates practicing in programs with low CNM involvement $(P<.003)$. However, there was no difference in those providing inpatient maternity care. Thirty-one percent of FM program directors and $25 \%$ of CNMs felt that physicians and CNMs have different ideas about how to treat patients; $26 \%$ of FM program directors who worked with midwives felt that CNMs should not be involved in residency curriculum planning.

CONCLUSIONS: CNM participation in FM residency education is very limited. Our study identified a gap between the current state and the preferences of CNMs and FM program directors for greater educational collaboration. Residency program director attitudes may contribute to the low rate of collaboration between the two fields.

(Fam Med. 2020;52(2):97-103.)

doi: 10.22454/FamMed.2020.548818

$\mathbf{T}$ he number of family physicians providing maternity care beyond residency has waned from $23.3 \%$ of practicing family phyisicians providing maternity care in 2000 to $9.7 \%$ in $2010 .^{1}$ This decline has contributed to a crisis of access to prenatal and intrapartum care in many rural communities. ${ }^{2}$

Beyond maternity care, the proportion of family physicians attending to the gender-specific health care needs of women in primary care settings is also declining. ${ }^{3}$

Family medicine (FM) residency programs must prepare future family physicians to serve essential patient and community needs in prenatal, perinatal, and women's health services. The success of certified nurse midwives (CNMs) within maternity care has led some educators and policy makers to hypothesize that collaborations with CNMs might encourage more family physicians to practice maternity care. ${ }^{1}$ Midwife-led models of maternity care have been shown to significantly lower the incidence of preterm birth and fetal loss, ${ }^{4}$ lower the rates of invasive procedures, ${ }^{5}$ and produce high patient satisfaction and continuity of care. ${ }^{6} \mathrm{CNMs}$ are well-suited to teach prenatal, intrapartum, and postpartum care to residents. Several studies have evaluated CNM involvement in medical student and resident (predominantly OB-GYN) education, ${ }^{7-18}$ but there are no studies yet that specifically explore the role of CNMs as teachers in FM.

Studies of CNMs within OB-GYN medical education indicate high levels of involvement, improved clinical experiences among those taught by midwives, and recognition of the importance of collaborative clinical relationships, teamwork, and interdisciplinary teaching. A national survey distributed to OB-GYN program directors in 1998 found that $54 \%$ of those residency programs

From the Department of Family Medicine (Drs Farahi and Sloane); School of Medicine (Ms Neylan); and Cecil G. Sheps Center for Health Services Research (Ms Silbersack), University of North Carolina at Chapel Hill; and MAHEC Family Medicine Residency Program, Asheville NC (Dr Oat-Judge). 
incorporated CNMs as educators. ${ }^{8}$ Of the CNMs surveyed (primarily CNMs recruited from the OB-GYN program directors), up to $66 \%$ of the CNMs were faculty for family medicine residents as well. ${ }^{8}$ By 2008 , a survey that targeted academic midwifery practices found that $80 \%$ of the practices were involved in teaching OB-GYN residents. ${ }^{7}$ Several case studies have also shown positive medical student and resident experiences; when asked to evaluate CNMs' formal involvement in educational settings, students and residents alike have consistently highly rated CNMs' teaching ability, perspective, and knowledge. ${ }^{9,13,15,19-20}$

To better characterize CNMs' involvement in the education of FM residents, we administered surveys to national samples of program directors of FM residency programs and CNMs involved in medical education. The study aimed to document the prevalence of various models of educational collaboration between FM educators and CNMs. Additionally, the study sought to characterize the attitudes of both disciplines toward collaboration.

\section{Methods \\ Overview}

We conducted two nationally representative surveys. The first was emailed to CNMs who are involved in medical education. This survey aimed to understand and characterize CNM roles within FM residency programs, as well as CNM attitudes, perceptions, and job satisfaction within medical education. The second survey was emailed to FM program directors and aimed to understand the prevalence and nature of CNM involvement in FM resident education, as well as program director attitudes and opinions regarding that involvement.

\section{Sample}

We identified CNM participants using the publicly-available directory of the Medical Education Caucus of the American College of NurseMidwives, which includes $195 \mathrm{CNMs}$ who are involved in teaching residents and/or medical students. Following initial survey distribution, 49 of the $195 \mathrm{CNM}$ contacts were deemed undeliverable due to invalid email addresses. This yielded a final sampling frame of 147 eligible CNMs who were either formally or informally involved in residency education. The survey asked CNMs about the specialties of the residents they were involved in teaching, and those who interacted with FM residents were asked to respond specifically regarding that experience.

To ensure a geographically representative sample of FM programs, we divided all programs listed in the American Academy of Family Physicians directory (including director names and emails) by region: Southern, Northeastern, Western, and Central. We randomly selected 50 programs within each region. Randomization was achieved using the random function within Microsoft Excel, to determine which 50 programs within each region the study team would reach out to. Of the initial sample population of 200 program directors, 20 were deemed undeliverable, yielding a final sampling frame of 180 programs.

\section{Recruitment}

We sent electronic surveys to participants and six follow-up emails to nonrespondents with another invitation to participate in the study. Of the 160 nonrespondent program directors, we selected 40 to receive follow-up phone calls inviting them to complete the survey via email or telephone with the study coordinator. We randomly selected 10 directors from each of the four regions, using the same randomization function within Excel, to have a representative follow-up list. Our CNMs recruitment relied on email only, as the database lacked contact phone numbers. An embedded consent form included at the start of each survey provided informed consent for participants. The UNC Chapel Hill Institutional Review Board approved all study procedures.

\section{Measures}

We provided separate surveys for the two study samples, though many questions were shared across both surveys. We adapted and modified survey elements from a previous national survey of CNMs with permission. ${ }^{7}$ To measure interprofessional collaboration, we used a modified version of questions developed by Kenaszchuk, et al. ${ }^{21}$ This scale was originally written for interprofessional collaboration between physicians and nurses or allied health professionals and was adapted to specify collaboration between physicians and CNMs. Of the 26 items in the original scale, we selected the six most relevant to FM-CNM collaboration and included them in both surveys.

The surveys used a typology of models of interaction between midwifery practices and residency programs adapted from Collins-Fulea. ${ }^{22}$ The models of interaction in this typology are: parallel interaction (in which CNMs practice in the same institution as a residency program, but have little interaction with the program), coexistence (in which there is informal interaction between CNMs and residency programs), blended interaction (in which CNMs have a private practice but also act as attending faculty or have other formal roles within the residency program), and fully integrated (in which CNMs dedicate their time to working with residents and do not have a private practice). This study changed the name of the coexistence model to "informal cooperation" and added a fifth category for no interaction.

\section{Data Collection and Analysis}

We gathered all data using the electronic survey platform Qualtrics, and entered CNM and FM program director contact information into a secure account. All subjects received an email invitation to participate in the study including an embedded hyperlink to the survey. To encourage participation, we sent follow-up emails to nonrespondents using the survey platform and the research 
coordinator's university email address.

We calculated descriptive data to describe the CNM and FM program director respondents, and tested differences between respondents and nonrespondents for statistical significance using the Wilcoxon signed rank test. The CNMs in our study sample were older than the average CNM $(P<.001){ }^{23}$ Additionally, responding FM programs were significantly larger in size than nonrespondents $(P<.001) .^{1 *}$ Due to the small sample size, we used the Fisher exact test to test for differences between models of CNM interaction by program size and region, and we used two-sample $t$ tests to determine the difference between models and average number of deliveries. We used Cochran-Mantel-Haenszel tests to determine the differences in means of the priority levels of midwife educational responsibilities, as rated by CNMs and program directors.

\section{Results}

From a sampling frame of 147 CNMs, 85 responses were eligible for analysis, yielding a response rate of $58 \%$; 106 of 180 FM program directors responded (59\% response rate).

Of the CNM sample, $87 \%$ were female, one was male (1\%), and the remainder $(12 \%)$ did not report their gender. The predominance of women in midwifery is consistent with surveys done by the American Midwifery Certification Board (AMCB) and the American College of Nurse Midwives (ACNM), which identified 99\% of respondents as female in 2010 and 2017 surveys. ${ }^{23-24}$ Additionally, $78 \%$ of the CNM respondents self-identified as white, $5 \%$ as black, $1 \%$ American Indian or Alaskan Native, and 1\% Asian, with $13 \%$ missing responses. These data are also comparable to the AMCB and ACNM surveys, which showed a majority of white respondents. ${ }^{23-24}$ The average age of CNM respondents was 58 years, with the youngest 41 and the oldest
72. Of the CNMs who responded, 38 interacted with FM residents, 62 with OB-GYN residents, 22 with emergency medicine residents, and four with other specialties.

Of the FM program director sample, $49 \%$ were male, $41 \%$ were female, and $10 \%$ were missing responses. The majority self-identified as white $(70 \%)$, with $4 \%$ identifying as black, $2 \%$ as Asian, and $1 \%$ each as American Indian/Alaskan $\mathrm{Na-}$ tive and Native Hawaiian/Pacific Islander. Nonresponse was $17 \%$ for this item. The average age of program directors was 50 years, with the youngest being 33 and the oldest being 68 .

Nearly two-thirds $(62 \%)$ of FM residency programs reported little to no interaction between midwives and residents (Figure 1). Of the programs that reported blended or full CNM interaction, the majority were large, with the southern region most highly represented (Table 1). Programs with higher levels of interactions with CNMs, defined as informal cooperation, blended interaction, and full integration with CNMs, reported statistically significantly higher percentages of graduates practicing prenatal care post residency (33\%) than those with low interaction (13\%; $P=.003)$. We found similar rates of graduates practicing inpatient maternity care, including attending deliveries, from high CNM interaction (19.4\%) and low interaction (16.8\%) programs $(P=.602)$. We found no association between CNM involvement in teaching and number of resident deliveries $(P=.642)$. Among CNMs who were employed by FM residency programs $(\mathrm{n}=38)$, $76 \%(\mathrm{n}=25)$ reported working full time (35 to 40 hours per week), $18 \%$ $(\mathrm{n}=6)$ worked part-time (10 to 35 hours), and 6\% (n=2) identified their employment as "other."

Table 2 shows responses from FM program directors, and from the subsample of CNMs who teach in FM, about priorities regarding educational roles for CNMs within residency programs. Program directors and CNMs were asked to rate the priority of certain educational roles of CNMs on a scale of 1 (not important), 2 (moderately important), and 3 (very important). Program directors tended to prioritize CNM involvement in supervising prenatal care, attending at resident deliveries, supervising postpartum care, and involving residents with CNM patients. CNMs prioritized these activities as well, but also highly rated their involvement in curriculum planning and serving as mentors for residents. Program directors and CNMs differed significantly in their rating of the following educational roles: CNM involvement in curriculum planning $(P=.0072)$, research $(P=.0163)$, mentoring (.0077), working with residents on CNMs' patients $(P=.0451)$, and attending residents' deliveries $(P=.0432)$. In general, CNMs assigned a higher priority to all listed educational activities than did FM program directors.

Table 3 compares responses of CNMs who are involved in FM teaching with those of FM program directors regarding their perception of the ideal role of CNMs in FM residency teaching. Eighty-eight percent of CNMs and $64 \%$ of program directors preferred high levels of CNM-FM interaction, with blended interaction being the preferred model. There was a nonsignificant trend for CNMs to favor a higher level of involvement than responding FM program directors $(P=.086)$, but the more striking contrast was between the current status (Figure 1) and the ideal status (Table 3).

\section{Discussion}

Our survey of $85 \mathrm{CNMs}$ involved in medical education and a geographically stratified random sample of 106 FM program directors revealed low rates of CNM involvement in FM residency training nationwide. $\mathrm{Al}-$ though both FM program directors and CNMs stated a preference for high-level collaboration through the blended interaction or fully integrated models, the current state of CNM interaction did not resemble these 
Table 1: Residency Program Involvement With Nurse Midwives by Selected Program Characteristic

\begin{tabular}{|c|c|c|c|c|c|c|c|c|c|}
\hline \multirow[t]{2}{*}{$\begin{array}{l}\text { Model of Nurse-Midwife } \\
\text { Interaction With Residency }\end{array}$} & \multirow[t]{2}{*}{$\begin{array}{c}\text { All FM } \\
\text { Programs }\end{array}$} & \multicolumn{2}{|c|}{$\begin{array}{l}\text { By Program } \\
\text { Size }^{\star} \\
P=.896\end{array}$} & \multicolumn{4}{|c|}{$\begin{array}{l}\text { By Geographic Region } \\
\qquad P=.652\end{array}$} & \multicolumn{2}{|c|}{$\begin{array}{l}\text { By Average \# } \\
\text { of Resident } \\
\text { Deliveries** } \\
\qquad P=.458\end{array}$} \\
\hline & & $\begin{array}{l}\text { Large } \\
\text { (73) }\end{array}$ & $\begin{array}{l}\text { Small } \\
(32)\end{array}$ & $\begin{array}{l}\text { Northeast } \\
\text { (30) }\end{array}$ & $\begin{array}{l}\text { South } \\
\text { (31) }\end{array}$ & $\begin{array}{l}\text { Midwest } \\
\text { (21) }\end{array}$ & $\begin{array}{l}\text { West } \\
\text { (23) }\end{array}$ & $\begin{array}{l}\text { Below } \\
\text { Mean }\end{array}$ & $\begin{array}{l}\text { Above } \\
\text { Mean }\end{array}$ \\
\hline $\begin{array}{l}\text { None. Residents have no midwifery } \\
\text { exposure at all-either directly or } \\
\text { indirectly. }\end{array}$ & $36 \%$ & $68 \%$ & $32 \%$ & $26 \%$ & $26 \%$ & $24 \%$ & $24 \%$ & $75 \%$ & $25 \%$ \\
\hline $\begin{array}{l}\text { Parallel. Midwifery practice exists } \\
\text { in same institution as residency } \\
\text { program, but there is little } \\
\text { interaction between midwives and } \\
\text { residents. }\end{array}$ & $26 \%$ & $63 \%$ & $37 \%$ & $30 \%$ & $19 \%$ & $26 \%$ & $26 \%$ & $74 \%$ & $26 \%$ \\
\hline $\begin{array}{l}\text { Informal cooperation. Midwifery } \\
\text { practice exists in same institution } \\
\text { as residency program, and midwives } \\
\text { help cover when residents are not } \\
\text { available, while they maintain a } \\
\text { private caseload/practice). This } \\
\text { model also involves informal } \\
\text { supervision and consultation } \\
\text { between midwives and residents. }\end{array}$ & $14 \%$ & $73 \%$ & $27 \%$ & $33 \%$ & $33 \%$ & $13 \%$ & $20 \%$ & $93 \%$ & $7 \%$ \\
\hline $\begin{array}{l}\text { Blended interaction. CNMs are } \\
\text { involved formally in residents' } \\
\text { education, but also maintain private } \\
\text { caseloads/private practice. }\end{array}$ & $18 \%$ & $74 \%$ & $26 \%$ & $26 \%$ & $53 \%$ & $5 \%$ & $16 \%$ & $67 \%$ & $33 \%$ \\
\hline $\begin{array}{l}\text { Fully integrated. Midwives are part } \\
\text { of residency program faculty, and do } \\
\text { not have a private practice/caseload. } \\
\text { Instead CNMs act on the resident } \\
\text { team, provide formal mentoring } \\
\text { and supervision clinically, as well as } \\
\text { academic lecturing and curriculum } \\
\text { planning. }\end{array}$ & $6 \%$ & $83 \%$ & $17 \%$ & $33 \%$ & $17 \%$ & $33 \%$ & $17 \%$ & $67 \%$ & $33 \%$ \\
\hline
\end{tabular}

* Large and small programs were defined as follows: small (six or fewer residents per year), large (seven or more residents in a year).

** Mean number of deliveries per resident over 3 years, all reporting programs=62.9 ( $\mathrm{n}=93)$.

Abbreviations: CNM, certified nurse midwife; FM, family medicine.

ideal models. Among CNMs who work full or part time within FM programs, an emphasis on clinical supervision and training was identified, with CNM respondents desiring more involvement in curriculum planning and resident mentorship.

Our study points to factors that may influence the discrepancy between the current and ideal models of educational collaboration. Possible reasons may include differing approaches to birth and tension between midwifery practice and medical education. ${ }^{8}$ Our surveys revealed that $31 \%$ of FM program directors and $25 \%$ of CNMs felt that physicians and CNMs have different ideas about how to treat patients, and CNM respondents were less likely to agree that the delineation of responsibilities between CNMs and residents was clear. Additionally, geographic variation in current CNM involvement suggests regional or historical contexts may help or hinder collaboration between disciplines. Lack of institutional support for midwives as teachers with protected administrative or teaching time has also been identified as a barrier. ${ }^{7}$

Of the FM program directors surveyed, $64 \%$ felt that formal involvement of CNMs in residency education was desirable. However, the results of our surveys revealed sparse CNM involvement. While this survey did not directly examine the barriers to collaboration between FM and CNMs, a plausible barrier may be the belief that nonphysicians are not appropriate teachers for FM residents; however, other nonphysician teachers, such as behavioral health specialists and clinical pharmacists, are often core educators within family medicine residencies. Finally, the Accreditation Council for Graduate Medical Education (ACGME) allows for nonphysician faculty to teach FM 
Table 2: Priority Level of Midwives as Educators in Family Medicine Residency Programs: Comparison of Nurse Midwife and Family Medicine Program Director Responses

\begin{tabular}{|l|c|c|c|}
\hline \multirow{2}{*}{\multicolumn{1}{|c|}{ Educational Role }} & \multicolumn{2}{c|}{$\begin{array}{c}\text { Mean (SD) Response } \\
\text { 1=Not Important, 2=Moderately } \\
\text { Important, 3=Very Important }\end{array}$} & $\begin{array}{c}\text { P Value for } \\
\text { Difference* }\end{array}$ \\
\cline { 2 - 4 } & \multicolumn{2}{c|}{$\begin{array}{c}\text { CNMs With FM } \\
\text { Resident Contact }\end{array}$} & FM Program Directors \\
\hline Lecturing & $2.13(.83)$ & $1.95(.71)$ & .4776 \\
\hline Involved in curriculum planning & $2.70(.48)$ & $1.73(.88)$ & $.0072^{* *}$ \\
\hline Researching & $2.00(.71)$ & $1.23(.59)$ & $.0163^{* *}$ \\
\hline Mentoring (formal advising) & $2.44(.73)$ & $1.50(.73)$ & $.0077^{* *}$ \\
\hline Working with residents on CNM's patients & $2.57(.68)$ & $2.17(.74)$ & $.0451^{* *}$ \\
\hline Supervising in prenatal care & $2.60(.74)$ & $2.21(.83)$ & .1421 \\
\hline Attending resident's deliveries & $2.80(.52)$ & $2.32(.89)$ & $.0432^{* *}$ \\
\hline Supervising in postpartum hospital care & $2.42(.77)$ & $2.13(.80)$ & .2221 \\
\hline Supervising in primary care & $1.67(.87)$ & $1.17(.34)$ & .0901 \\
\hline
\end{tabular}

* Calculated with Cochran-Mantel-Haenszel Statistic.

** Significance at $P=.05$.

For exact wording of the question, refer to the survey in the Appendix.

Abbreviations: CNM, certified nurse midwife; FM, family medicine.

Table 3: Ideal Role of CNMs in Residency Training: Comparison of CNM and Program Director Opinions

\begin{tabular}{|l|c|c|}
\hline \multicolumn{1}{|c|}{ Model of Nurse-Midwife Interaction With Residency } & $\begin{array}{c}\text { CNMs With FM } \\
\text { Resident Contact } \\
\text { (n=33) }\end{array}$ & $\begin{array}{c}\text { FM Program } \\
\text { Directors } \\
\text { (n=97) }\end{array}$ \\
\hline None. Residents have no midwifery exposure at all-either directly or indirectly. & $0 \%(0)$ & $7 \%(7)$ \\
\hline $\begin{array}{l}\text { Parallel. Midwifery practice exists in same institution as residency program, but } \\
\text { there is little interaction between midwives and residents. }\end{array}$ & $6 \%(2)$ & $9 \%(9)$ \\
\hline $\begin{array}{l}\text { Informal cooperation. Midwifery practice exists in same institution as residency } \\
\text { program, and midwives help cover when residents are not available, while } \\
\text { they maintain a private caseload/practice). This model also involves informal } \\
\text { supervision and consultation between midwives and residents. }\end{array}$ & $6 \%(2)$ & $20 \%(19)$ \\
\hline $\begin{array}{l}\text { Blended interaction. CNMs are involved formally in residents' education, but also } \\
\text { maintain private caseloads/private practice. }\end{array}$ & $55 \%(18)$ & $45 \%(44)$ \\
\hline $\begin{array}{l}\text { Fully integrated. Midwives are part of residency program faculty, and do not } \\
\text { have a private practice/caseload. Instead CNMs act on the resident team, provide } \\
\text { formal mentoring and supervision clinically, as well as academic lecturing and } \\
\text { curriculum planning. }\end{array}$ & $33 \%(11)$ & $19 \%(18)$ \\
\hline
\end{tabular}

Abbreviations: CNM, certified nurse midwife; FM, family medicine.

residents as long as they maintain the certifications and qualifications required by their specific field. ${ }^{25}$

As the health care system has grown more complex, a premium has been placed on interdisciplinary care. As a result, there is a need to train residents in interdisciplinary teams to prepare them to thrive in a teambased care environment after graduation. ${ }^{26}$ With CNMs' enthusiasm to serve as teachers for FM residents, there is an opportunity to increase interdisciplinary education in family medicine maternity care. CNMs consistently prioritized resident mentoring and resident curriculum development higher than FM program directors. For residency program directors, CNMs may represent a largely untapped pool of mentors and curricular champions. For the residents, focused teaching from CNMs would provide them with immersion in a style and culture of care that they may not otherwise experience, and that is associated nationally with improved maternal and neonatal outcomes and is in line with family medicine values such as personalized care and avoidance of overuse of technology. The potential 
Figure 1: Current Model of Nurse Midwife Interaction With Family Medicine Residents, as Reported for Family Medicine Residency Program Directors

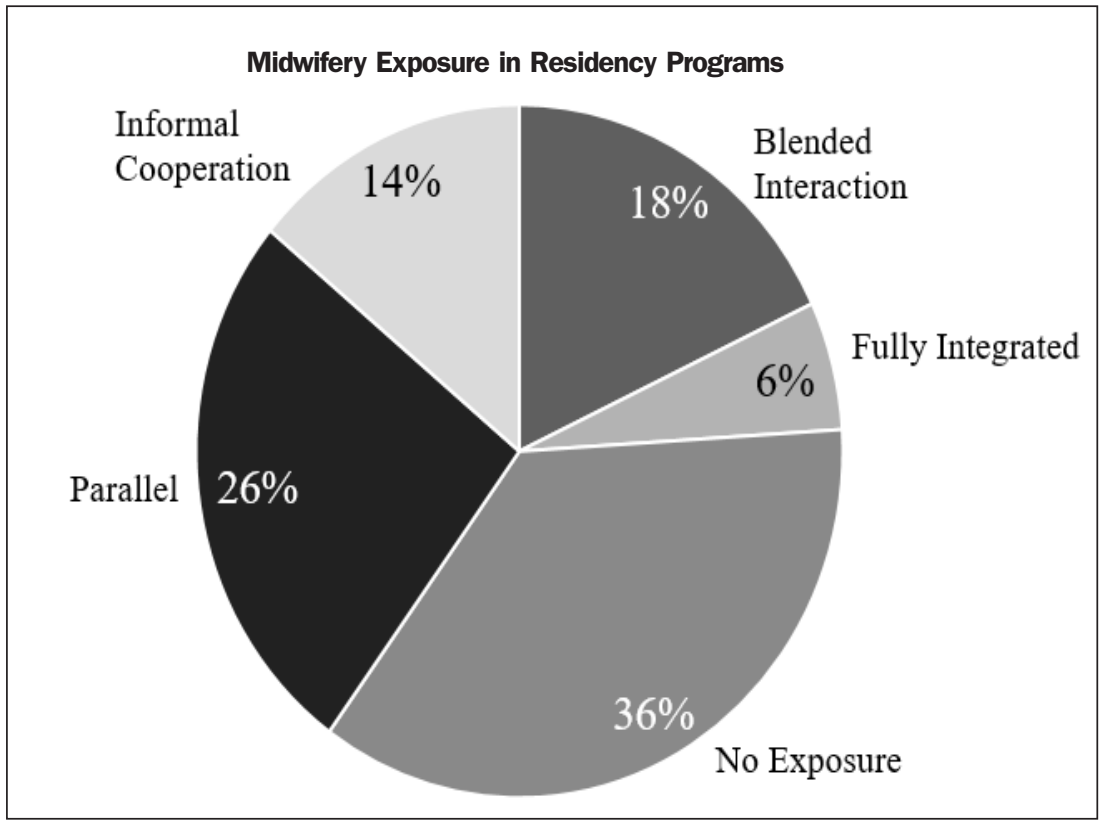

benefit of this exposure could carry into their postresidency work.

Our study has several limitations. First, our initial attempts to distribute the survey to program directors revealed that numerous contact names and contact information were outdated. Similarly, CNMs were selected from a database that had not been updated for over 5 years. As a result, some CNMs who currently teach may have been omitted. In addition, our less-than-complete response rate overall and to specific questions may limit the generalizability of these findings. However, response rates near $60 \%$ are relatively high for online surveys of professionals, and response rates to questions within the tool were generally $90 \%$ or higher, with the lowest rates being for demographic data, as these were at the end of the survey. Additionally, our survey did not differentiate between FM residency programs that emphasize maternity care and those that do not. Given that FM residency requirements include obstetric training, we felt that it was reasonable to survey all programs.

While our study shows low rates of CNM involvement in FM resident

\section{Footnote}

* We received a document with nonrespondent data on FM programs via personal correspondence from a representative from the AAFP.

ACKNOWLEDGMENTS: This study received support from the University of North Carolina at Chapel Hill Department of Family Medicine and the Department of Family Medicine Summer Research Academy, and from the Elizabeth and Oscar Goodwin Endowment. It was approved by the UNC Institutional Review Board (Study \# 18-0441).

Portions of this research were presented at UNC-Chapel Hill Medical Student Research Day, October 29, 2018.

CORRESPONDING AUTHOR: Address correspondence to Dr Narges Farahi, Department of Family Medicine, University of North Carolina at Chapel Hill, 590 Manning Drive, Chapel Hill, NC 27514. 412-657-5728. Fax: 984-9746125.narges_farahi@med.unc.edu.

\section{References}

1. Tong ST, Makaroff LA, Xierali IM, Puffer JC, Newton WP, Bazemore AW. Family physicians in the maternity care workforce: factors influencing declining trends. Matern Child Health J. 2013;17(9):1576-1581.

2. Hung P, Kozhimannil KB, Casey MM, Moscovice IS. Why are obstetric units in rural hospitals closing their doors? Health Serv Res. 2016;51(4):1546-1560.

3. Xierali IM, Puffer JC, Tong STC, Bazemore AW, Green LA. The percentage of family physicians attending to women's gender-specific health needs is declining. J Am Board Fam Med. 2012;25(4):406-407.

4. Sandall J, Soltani H, Gates S, Shennan A, Devane D. Midwife-led continuity models versus other models of care for childbearing women. [Review]. Cochrane Database Syst Rev. 2016;4:CD004667.

5. Newhouse RP, Stanik-Hutt J, White KM, et al. Advanced practice nurse outcomes 1990-2008: a systematic review. Nurs Econ. 2011;29(5):230-250.

6. King TL, Laros RK Jr, Parer JT. Interprofessional collaborative practice in obstetrics and midwifery. Obstet Gynecol Clin North Am. 2012;39(3):411-422.

7. McConaughey E, Howard E. Midwives as educators of medical students and residents: results of a national survey. J Midwifery Womens Health. 2009;54(4):268-274.

8. Harman PJ, Summers L, King T, Harman TF. Interdisciplinary teaching. A survey of CNM participation in medical education in the United States. J Nurse Midwifery. 1998;43(1):27-37.

9. Angelini DJ, O'Brien B, Singer J, Coustan DR. Midwifery and obstetrics: twenty years of collaborative academic practice. Obstet Gynecol Clin North Am. 2012;39(3):335-346.

10. Appleton S, Nacht A. Interdisciplinary education from a college of nursing and school of medicine. J Midwifery Womens Health. 2015;60(6):744-750. 
11. Blanchard MH, Kriebs JM. A successful model of collaborative practice in a university-based maternity care setting. Obstet Gynecol Clin North Am. 2012;39(3):367-372.

12. Cooper EM. Innovative midwifery teaching for medical students and residents. J Midwifery Womens Health. 2009;54(4):301-305.

13. Cotter D, Turner MJ, McAuliffe FM, Higgins MF. Medical students learning experiences of the labour ward: a qualitative research study. Eur J Obstet Gynecol Reprod Biol. 2016;206:204-207.

14. DeJoy S, Burkman RT, Graves BWG, et al Making it work: successful collaborative practice. Obstet Gynecol. 2011;118(3):683-686.

15. Feinland JB, Sankey HZ. The obstetrics team: midwives teaching residents and medical students on the labor and delivery unit. J Midwifery Womens Health. 2008;53(4):376-380.

16. Howard FM, Leppert PC. Reaction of residents to a teaching collaborative practice. J Nurse Midwifery. 1998;43(1):38-40.

17. Cordell MN, Foster TC, Baker ER, Fildes B. Collaborative maternity care: three decades of success at Dartmouth-Hitchcock Medical Center. Obstet Gynecol Clin North Am. 2012;39(3):383-398
18. Pecci CC, Mottl-Santiago J, Culpepper L, Hef fner L, McMahan T, Lee-Parritz A. The birth of a collaborative model: obstetricians, midwives, and family physicians. Obstet Gynecol Clin North Am. 2012;39(3):323-334.

19. Afriat CI. Nurse-midwives as faculty preceptors in medical student education. J Nurse Midwifery. 1993;38(6):349-352

20. Angelini DJ, Afriat CI, Hodgman DE, Closson SP, Rhodes JR, Holdredge A. Development of an academic nurse-midwifery service program. A partnership model between medicine and midwifery. J Nurse Midwifery. 1996;41(3):236242

21. Kenaszchuk C, Reeves S, Nicholas D, Zwarenstein M. Validity and reliability of a multiplegroup measurement scale for interprofessional collaboration. BMC Health Serv Res. 2010;10(83):83

22. Collins-Fulea C. Models of organizational structure of midwifery practices located in institutions with residency programs. J Midwifery Womens Health. 2009;54(4):287-293.

23. American College of Nurse Midwives. The ACNM core data survey. Silver Spring, MD ACNM; 2010. http://www.midwife.org/ACNM/ files/ccLibraryFiles/Filename/000000001720/ CoreDataSurvey_2010_one-pager.pdf. Accessed October 15, 2018.
24. McFarlin BL, Tanner T, Emeis CL, et al. 2017 Task Analysis: A report of midwifery practice. American Midwifery Certification Board. https://www.amcbmidwife.org/docs/defaultsource/task-analysis/2017-task-analysis-report. pdf?sfvrsn=7aaa6e17_2. Accessed October 16 2019.

25. Accreditation Council for Graduate Medical Education. Program requirements for graduate medical education in family medicine. Chicago: ACGME; 2018. https:// www.acgme.org/Portals/0/PFAssets/Progr amRequirements/120FamilyMedicine2018. pdf?ver=2018-06-15-112624-307. Accessed December 13, 2018.

26. Schuetz B, Mann E, Everett W. Educating health professionals collaboratively for teambased primary care. Health Aff (Millwood) 2010;29(8):1476-1480 